\title{
The Effectiveness of Pictured Letters Mnemonics Strategy in Learning Similar English Language Letters among Students with Learning Disabilities
}

\author{
Maysoon A. Dakhiel ${ }^{1, *} \&$ Mohammed O. Abu Al Rub ${ }^{1}$ \\ ${ }^{1}$ Curriculum and Instruction of English Language, Faculty of Education, Jeddah University, Saudi Arabia \\ *Correspondence: Curriculum and Instruction of English Language, Faculty of Education, University of Jeddah, \\ Saudi Arabia.
}

Received: October 28, 2017

Accepted: November 13, 2017

Online Published: November 29, 2017

doi:10.5430/wje.v7n6p21

URL: https://doi.org/10.5430/wje.v7n6p21

\begin{abstract}
The present study aims to investigate the effectiveness of pictured letters mnemonics strategy in learning similar English language letters among students with learning disabilities in Saudi Arabia according to experimental group (1) and (2), control group, gender, and interaction between them. The study sample comprised (90) students with learning disabilities who were randomly distributed to three equal groups. While the first experimental group was taught using the modified letter method, the second experimental group was taught using the method of both modified and abstract letters, and the control group was taught in the traditional way. To measure the effectiveness of the strategy, the authors applied (pre, post, and follow-up) tests. As a result, two-way ANOVA indicated that there were significant differences attributed to the teaching method, in favor of the method of both modified and abstract letters, while there were no statistically significant differences due to gender or interaction between the teaching method and gender. The same results were obtained from the follow-up test. Accordingly, a set of recommendations were made.
\end{abstract}

Keywords: Pictured letters strategy; Mnemonics; Arabic letters; learning disabilities

\section{Introduction}

Many individuals with learning disabilities suffer while remembering what has been learned. As a result, they cannot make use of such learning to facilitate further learning. Reading letters of similar form is the most difficult part because they feel confused (Mather and Healey, 1984). Therefore, memory plays a key role in learning that is an effective process involving diverse information received by the various senses, to be retrieved when needed. Individuals use a variety of ways to remember, including repetition, classification depending on a common property, using charts and summaries to link the new and former learning with respect to the academic content, or taking notes and making charts for easy retrieval by the external memory.

Normal individuals use many strategies, which they develop independently, to save and retrieve information when needed, while those with learning disabilities need others to teach them and cannot utilize such strategies on their own (Mastropieri, Sweda and Scruggs, 2005). Hallahan et al. (2007) argue that students with learning disabilities lack some strategies of the working memory that transmit information into the long-term memory. They also suffer from the inappropriate practices of such strategies, as well as the lack of understanding what strategies to use and when to use them. Furthermore, individuals with learning disabilities are less efficient than the normal in regard to auditory and visual memory. They have problems in pursuing the appropriate strategies that help them integrate the new and former knowledge.

Students with learning disabilities experience difficulties with letters of similar forms. For example, a student may pronounce "d" as "b" and vice versa. This problem is repeated with other similar English language letters such as 'W' and 'M'. Mather and Healey (1984) postulated that students confuse similar letters and they have problems with writing, numeracy, spelling as well as linguistic problems in both receptive and expressive situations. In addition, they have cognitive, auditory or visual, attention deficit, attention deficit hyperactivity disorder, behavioral and 
emotional, and social problems. They also reported that individuals with learning disabilities have low self-esteem and peer rejection as well as motivation and memory problems (Steele, 2007).

Several methods have been introduced to increase the individual's ability to remember and retain information as long as possible, including the methods that improve attention, increase meaningful learning, use external memory, activate practice and repetition, and use the word-based mnemonics strategy, which is derived from the Latin word (Mnemosyne) (Shmedman and Ehri, 2010).

Mnemonics strategies are seen as both memory and learning strategies. They help make unfamiliar information more familiar and realistic by linking the new to old information, using visual or audio hints. It is used to clarify information making it meaningful by linking it to known objects to improve learning (Rack, 2005).

Such strategies are more effective when learning materials that cover tangible physical stimuli that are better received by the senses than abstract ones. Students with learning disabilities will benefit more from illustrations and using mnemonics strategies to learn unfamiliar vocabulary and identify and explore the main idea (Mastropieri, Sweda and Scruggs, 2000).

There are different mnemonics strategies that are used to maintain and recall information in the long-term memory. For example, the keyword strategy is used to memorize foreign vocabulary by linking the foreign word with a word from the mother tongue. Thus, they are totally or partially similar. The Location Strategy (LOCI) is based on the idea of remembering a familiar set of places and linking them to the content to be remembered. Accordingly, the mental travel of those places will help in remembering the associated academic content. The acronyms strategy is based on taking the initial letters of the names or content required to be learned and use inferences to symbolize a word or more to serve as a shortcut to those names or contents. The peg word strategy, which is mainly used to remember lists, is based on linking words that have the same rhythm or sound, then creating mental links of these relations, while the ode or rhyme strategy concentrates on using the words to be remembered in a poem and links them to other words by rhyming, and the story strategy depends on connecting the things to be remembered with an innovative story. Yet, the metamemory strategy is related to thinking about the cognitive processes performed by observing, controlling, and directing them. While the ridiculous association strategy helps link the content to be remembered for a cynical or ridiculous story or incident, the Visualization Strategy works through imaginative images, which means that the learner conjures up an imagined picture of the experiences to be learned. Finally, the embedded pictureletter strategy is based on drawing the letters in the form of things whose name begins with the same sound and form of the letter (Miqdad and Kanana, 2014).

In the pictured letters strategy, the letters are converted into familiar shapes. Accordingly, they resemble the shape of the letter, and the label of the shape begins with the same letter. For example, in 'flower', ' $F$ ' is drawn in the shape of a flower $f^{*}$, ' $T$ ' in 'Table Lamp' is drawn as ( $\mathbb{T}$ ), and ' $g$ ' in 'glasses' is presented like ( ${ }^{e g}$ ) highlighting on half of the image to represent the letter ' $\mathrm{g}$ '.

Therefore, mnemonics strategies help improve learning and remembering among the different groups of learners within diverse educational and cultural contexts. However, only a few studies on teaching English to students with learning disabilities or teaching students to use mnemonics strategies to help them learn languages. Thus, the current study attempts to investigate the use of the embedded picture-letter strategy with students with learning disabilities.

\section{Statement of the Problem}

Learning similar English language letters is a challenge to students with learning disabilities. They may feel confused because they fail to remember the differences between them, which hinder their ability to read and acquire knowledge. Thus, they are not progressed to advanced reading levels. This is negatively reflected in their academic performance. Many learning and memory strategies were formerly used to overcome this problem. However, the application of mnemonics strategy to students with learning disabilities to learn the English language letters has not been explored. Therefore, the authors feel that there is a need to develop this strategy to enable students with learning disabilities to learn, remember and distinguish between the letters of the English language. Accordingly, the current study attempts to answer the following questions:

- Does the performance of students with learning disabilities differ in learning the similar English language letters in the post-test with the difference of the teaching method, gender, and interaction?

- Does the performance of students with learning disabilities differ in learning the similar English language letters in the follow-up test with the difference of the teaching method, gender, and interaction? 


\section{Significance}

It is hoped that this study contributes to the literature by helping resource rooms' teachers and EFL teachers in the instruction of similar English language letters to students with learning disabilities that often experience confusion when learning these letters, forget their forms, and find it difficult to read. It helps clearly illustrate the simple differences between such letters and adopt drawing strategy. Furthermore, it is expected to provide guidance that enables program designers and curriculum developers for students in the first three primary grades, kindergarten, and the programs of children with learning disabilities to consider including the pictured letters mnemonics strategy in the curricula offered to these students.

\section{Objectives}

The current study aims to:

- Recognize the effectiveness of pictured letters mnemonics strategy in learning similar English language letters for students with learning disabilities.

- Identify the performance of students with learning disabilities in the post-test of teaching similar English language letters according to the teaching method, gender, and interaction between them.

\section{Limitations}

The current study has been limited to:

Spatial limitations: Learning disabilities resource rooms of the General Directorate of Education in Jeddah.

Temporal limitations: The second semester of the scholastic year 2016/2017.

It has also been limited to:

- The study tools, procedures for development, and accuracy of data they were used to collect.

- The study population and sampling; it was limited to students with learning disabilities in schools with resource rooms in the General Directorate of Education in Jeddah. A sample of students who mix reading the same English language letters was intentionally selected.

- Sample's size, characteristics, and selection.

\section{Definition of Terms}

Students with learning disabilities: Those students enrolled in the resource rooms in the General Directorate of Education in Jeddah. According to the classification criteria used in schools, including the application of standardized and non-standardized tests, as well as data collection methods including teachers' observations, case studies, and family interviews, they were characterized that they experience confusion in reading similar English language letters.

Teaching similar English language letters: The degree obtained by the student participating in the three groups on the three equal form of the improved achievement tests (pre-test, post-test, and follow-up test) to measure the student's learning of similar English language letters. The total marks for each three ranges between $(0-26)$.

\section{Literature Review}

Many studies demonstrate the effectiveness of mnemonics strategies with all learners, regardless of age and mental abilities. However, students with learning disabilities who have been taught using mnemonics strategies excelled their peers who have not used such strategies to learn and remember new and unfamiliar content related to school. Such strategies are more effective when learning materials express tangible physical stimuli that the senses perceive better than abstract ones.

For example, the results of Mastropieri, Sweda, and Scruggs (2000) supported the idea that students with learning disabilities would benefit more from illustrations and using mnemonics strategies to learn unfamiliar vocabulary and identify and explore the main idea.

White (2006) investigated the effectiveness of a mnemonics strategy to remember the pictured letters associated with the acquisition of labels and sounds of letters among (32) at-risk kindergarten students in Texas. They were compared with other students in a control group who were taught using the unrelated pictured letters (the figure is 
not the same as the letter, but it starts with its label). Results showed that students who were taught using the mnemonics strategy learned more letters' labels than those of the control group. This strategy positively affected the long-term memory. This was reflected in the increased ability to label the letters in the immediate and delayed posttest.

DiLorenzo et al. (2010) compared a program to recognize letter sounds via pictured letters mnemonics with a multisensory strategy, namely "Itchy's Alphabet" with traditional kindergarten curricula. The sample comprised three kindergarten classrooms. Results showed that there was a statistically significant impact in favor of Itchy's Alphabet strategy on students' ability to recognize the sounds of initial letters, the fragmentation of words into their individual sounds, and decoding verbal absurdity.

Sehlberg, Barendregt, and Rubens (2011) aimed to teach the letters of the Chinese language as a second language to Japanese students in a game that utilized pictured letters mnemonics strategy. This study was applied to (136) Japanese students aged (10-30), who received three to four play sessions, ranging (45-75) minutes per each. Results showed that there were differences in favor of teaching kanji (Chinese letters) using pictured letters mnemonics strategy and that education was more enjoyable.

Sener and Belfiore (2005) aimed at checking the effectiveness of pictured letters mnemonics strategy in naming silent letters and producing their sounds for three $4^{\text {th }}$ grade Turkish students who were at risk of EFL failure. Results showed that all three students mastered naming and producing silent letters while retaining what they have learned for a week after the intervention. They also demonstrated the ability to disseminate information and produce words that begin and end with a consonant sound.

Manalo, Mizutani, and Trafford (2004) investigated the effect of additional instructional courses using pictured letters mnemonics strategy to facilitate the learning and meanings of Hiragana and Katakana letters in a sample of (27) $1^{\text {st }}$-year university students enrolled and experienced difficulties in the Japanese language course. Results indicated that although there were no statistically significant differences in the actual grades of students after attending additional educational sessions, their success rate increased.

\section{Methodology}

This section presents the participants in the current study, method, and criteria of their selection, how to develop the study tools and checking their validity and reliability, procedures for implementing the training program and the educational session, study variables, and statistical analyses and their use.

\subsection{Population and Sampling}

The study population comprised all students with learning disabilities enrolled in the resource rooms at the schools of the General Directorate of Education in Jeddah. The sample consisted of 90 students who were intentionally selected because they experience confusion in similar English language letters. Additionally, they and their parents and teachers desire to participate and continue the current study. They were randomly distributed to the three groups, each of which comprised 15 male and 15 female students. Table 1 shows the distribution of the study sample.

Table 1. Distribution of the Study Sample

\begin{tabular}{cccc}
\hline Group & Males & Females & Total \\
\hline Method of teaching the modified letter & 15 & 15 & 30 \\
Method of teaching the modified and abstract letters & 15 & 15 & 30 \\
Traditional method of teaching letters & 15 & 15 & 30 \\
Total & 45 & 45 & 90 \\
\hline
\end{tabular}

\subsection{Tools of the Study}

The study tools covered a description of individual educational plans regarding the three teaching methods adopted by the program, educational and evaluation worksheets, similar English language letters developed using pictured letters strategy, and achievement tests used to collect data to be statistically analyzed.

\subsubsection{The Developed Training Program}

The authors developed a training program that included educational plans for each of the three teaching methods: 
a. The method of teaching the modified letter: It includes individual educational plans to teach the similar English language letters numbered (26), educational and evaluation worksheets that aimed at helping students learn and remember the similar English language letters by drawing familiar shapes with the background of the letter. As a result, it resembles the letter to be taught and its title begins with the sound of the letter.

b. The method of teaching the modified and abstract letters: It includes the letters modified in the first method that are associated with the abstract ones beside them.

c. The traditional method of teaching letters: It is the traditional teaching method used in the teaching of letters, including abstract letters along with pictures of familiar things. The label of the thing shall begin with the sound of the initial letter, but it does not require that the shape is close to the shape of the letter.

The program was prepared based on the expertise of the specialists of learning disabilities and those of English language in teaching students with learning disabilities and theoretical literature. In their formulation and writing, effective teaching methods were followed, including the presentation of the task in a series (skill analysis); repetition, practice, and serial review; learning ways of asking questions, and controlling the level of the task's difficulty (from easy to difficult), individual education, and small groups. The training program consisted of:

- The pictured letters: A set of pictured letters of the similar English language letters were developed by drawing familiar images in their background. They should have a similar form of the letters by nature or they seemed similar after modification. The label of the shape shall begin with the sound of the indicating letter. Therefore, the authors benefited from the literature that highlighted a part of the image similar to the letter, at the expense of the other parts. Thus, the parts resembling the letter were painted in dark colors, while the other parts took light ones.

- Educational plans: Educational plans for each of the three teaching methods to teach each letter according to the methods of effective teaching were made to control the impact of the variables of the teacher's experience and qualification in teaching planning. As a result, a plan was made according to each method and to teach each letter.

- Worksheets: Two training worksheets were designed for each letter; one educational and the other evaluation, as follows:

a. The educational worksheet contained a picture of the letter according to the method of teaching without colors. The student is asked to paint it in addition to the dotted letter. S/he is asked to connect the dots to form the letter, as well as the regular lines below to copy the letter.

b. Evaluation worksheet: A standardized worksheet for all groups was designed to ascertain the extent of learning in the study groups. It comprised words containing the letter to be taught. The students were asked to circle around the desired letter. Furthermore, the words were carefully selected to be appropriate for students with learning disabilities.

- Achievement tests: An achievement test, consisting of three equivalent tests (i.e. pre-test, post-test, and followup test), was designed to measure students' knowledge of the similar English language letters, as follows:

a. Pre-test is a test to identify the initial letter of the picture by circling around it. The test comprised (26) paragraphs; the number of the English language letters in the form of pictures of familiar objects. Under each picture, four similar letters (either in the form or sound) were written. The students should circle around the initial letter of the shape's label that each student gets (1) mark if a circle is placed on the correct letter and (0) mark if s/he selected the wrong, did not select any letter, or selected more than one.

b. Post-test is a test to identify the initial letter of the picture's label by matching the picture to the letter. The test comprised (26) paragraphs representing familiar pictures. Under each picture, four similar letters (either in the form or sound) were written. The students should match the picture to the correct letter. Thus, $\mathrm{s} / \mathrm{he}$ gets (1) mark if the matching is done correctly and (0) mark if s/he matches it wrongly, does not draw any line, or matches the line to more than one letter.

c. Follow-up test is a test to identify the initial letter of the picture's label. The test consisted of 26 paragraphs divided into two parts. In the first part, the student was asked to identify the initial letter of the label of the figure in the picture by circling around it. In the second part, s/he was asked was asked to identify the initial letter of the figure by matching the figure to the letter. In the first part, the student obtains (1) mark if s/he circled the correct letter and (0) mark if s/he selects the wrong letter, does not select any letter, or selects 
more than one letter. In the second part, the student gets (1) mark if the matching is done correctly and (0) mark if $\mathrm{s} /$ he matches it wrongly, does not draw any line, or matches the line to more than one letter.

\subsection{Procedures}

To conduct the study, the following stages were taken:

- The tools, including modified letters, tests, educational plans, and educational and evaluation worksheets, were submitted to specialists to test their validity and reliability. Accordingly, the proposed modifications were made to them.

- Two models of some letters were created and presented to a group of specialists to select the most appropriate ones. The letters that got the highest agreement of the two models were maintained. Then, they were presented to a group of students with learning disabilities, as a pilot study, to ascertain their familiarity with the students.

- The reliability of achievement tests was calculated using Pearson correlation and alpha Cronbach coefficients. It was found that alpha Cronbach coefficient for the pre, post, and follow-up tests was $(0.83),(0.88)$, and $(0.85)$ which were appropriate values for the current study.

- After getting the approval of the guardians and according to the conditions of the test, a sample of students was tested because of the lack of available choices and the distribution of participants to the three groups of study (two experimental and one control).

- A timetable for the application of the program was set to (13) weeks. In the first week, teachers were trained on what should be done in school and the pre-test. Then, (9) weeks were spent on the actual application of the program; two sessions a week. In the $11^{\text {th }}$ week, the post-test was done that was followed by two weeks of nonintervention. Finally, in the $13^{\text {th }}$ week, the follow-up test was done.

\subsubsection{Implementation of the Educational Session}

For (13) weeks, training sessions were applied to small groups of students. In each week, (2) sessions were conducted; about (14) training hours. Additionally, there were intervals after teaching and evaluation. Each session was applied, as follows:

1. The letter card was placed in front of the student according to the teaching method applied to the group s/he belonged to (i.e. the method of teaching the modified letter, the method of teaching the modified and abstract letters, and the traditional method of teaching letters). Then, the letter was written on the board.

2. The student was asked to label the picture on the card. While the correct answer was confirmed, the wrong one was modified.

3. The student was asked about the picture in the background of the letter like the modified letter or the one beside the picture. While the correct answer was confirmed, the wrong one was modified.

4. An educational worksheet with the picture of the letter according to the method adopted by the group the student belonged to was displayed to the student. Then, he was asked to color the letter within the picture, as well as the abstract letter, if any. S/he was asked to match dotted lines to form the letter and copying the letter on the blank line beneath.

5. After completing the educational worksheet, an evaluation worksheet was submitted to the student to test student's learning, composed of words that were carefully selected from literature (Yahya, 2007). The student was asked to circle the letter. Then, the educational and evaluation worksheets were corrected and saved in the program file to perform the statistical analysis later.

\subsubsection{Variables}

Independent variables

- Teaching method including (3) levels (i.e. method of teaching the modified letter, method of teaching the modified and abstract letters, and traditional method of teaching letters)

- Gender including (2) levels (male and female)

Dependent variable: Teaching similar English language letters tested by the three achievement tests.

Statistical Analysis

The quasi-experimental method was adopted as the most appropriate to the study's objectives because of the difficulty of the random selection of the participants. To answer the study questions, arithmetic means, standard 
deviations, and modified means. To show the significance of statistical differences between the arithmetic means, Two-Way ANCOVA and LSD (Least Significant Difference) were used.

\section{Results}

To check the equivalence of the three groups of study and select the appropriate statistical analysis approach, arithmetic means, standard deviations, and modified means were calculated for the performance of all participants in the post-achievement test. Results showed that there was an apparent contradiction among the study groups, indicating their inequivalence. As a result, Two-Way ANCOVA was used, as shown in table (2).

Table 2. Arithmetic Means and Standard Deviations of the Post-Test According to the Teaching Method and Gender

\begin{tabular}{ccccc}
\hline Teaching Method & Gender & Arithmetic Mean & Standard Deviation & Number \\
\hline Modified Letter & Male & 5.65 & 5.239 & 15 \\
& Female & 6.43 & 5.150 & 15 \\
& Total & 6.10 & 5.206 & 30 \\
Interaction between the & Male & 4.15 & 3.814 & 15 \\
modified and abstract & Female & 3.20 & 3.125 & 15 \\
letters & Total & 3.30 & 3.561 & 30 \\
Traditional & Male & 8.50 & 5.216 & 15 \\
& Female & 9.40 & 5.017 & 15 \\
& Total & 9.20 & 5.028 & 30 \\
Total & Male & 6.00 & 5.211 & 45 \\
& Female & 6.40 & 5.372 & 45 \\
& Total & 6.01 & 5.136 & 90 \\
\hline
\end{tabular}

Table (2) shows variance among the study groups that indicates non-equivalence. It was noted that the method of teaching the modified letter achieved an arithmetic mean of (6.10) and a standard deviation of (5.206), while the method of teaching the modified and abstract letters achieved an arithmetic mean of (3.30) and a standard deviation of (3.561). The traditional method of teaching letters achieved an arithmetic mean of (9.20) and a standard deviation of (5.028). To show the significance of the arithmetic means, two-way ANCOVA was used, as shown in table (3).

Table 3. Two-Way ANCOVA of the Effect of Teaching Method and Gender and Their Interaction in the Pre-Test

\begin{tabular}{cccccc}
\hline Source of variance & $\begin{array}{c}\text { Total Sum of } \\
\text { Squares }\end{array}$ & $\begin{array}{c}\text { Freedom } \\
\text { Degrees }\end{array}$ & $\begin{array}{c}\text { Means of } \\
\text { Squares }\end{array}$ & $\begin{array}{c}\text { "F" } \\
\text { Value }\end{array}$ & Significance \\
\hline Teaching Method & 386.564 & 2 & 193,27 & 8.364 & Statistics \\
Gender & 2.785 & 1 & 2.785 & 0.142 & 0.728 \\
Interaction between & 16.472 & 2 & 8.236 & 0.352 & 0.711 \\
Gender\& Teaching & & & & & \\
Method & & & & & \\
Error & 1345.850 & 84 & 24.653 & & \\
Total & 2435.215 & 89 & & &
\end{tabular}

Table (3) shows that there was a statistically significant effect of the teaching method, while there was no statistically significant difference of gender nor interaction between them

To answer the first question "does the performance of students with learning disabilities differ in learning the similar English language letters in the post-test with the difference of the teaching method, gender, and interaction?", the 
arithmetic means, standard deviations, and modified means in the post-test were calculated according to the teaching method and gender, as shown in table (4).

Table 4. Arithmetic Means, Standard Deviations, and Modified Means of the Performance of the Participants in the Post-Test According to the Teaching Method and Gender

\begin{tabular}{lccccccc}
\hline & \multicolumn{2}{c}{ Pre-Test } & \multicolumn{3}{c}{ Post-Test } \\
Teaching & Gender & $\begin{array}{c}\text { Arithmetic } \\
\text { Method }\end{array}$ & $\begin{array}{c}\text { Standard } \\
\text { Deviation }\end{array}$ & $\begin{array}{c}\text { Arithmetic } \\
\text { Mean }\end{array}$ & $\begin{array}{c}\text { Standard } \\
\text { Deviation }\end{array}$ & $\begin{array}{c}\text { Modified } \\
\text { Means }\end{array}$ & $\begin{array}{c}\text { Numbe } \\
\mathrm{r}\end{array}$ \\
\hline Modified Letter & Male & 5.65 & 5.239 & 16.70 & 3.361 & 16.781 & 15 \\
& Female & 6.43 & 5.150 & 16.90 & 3.485 & 16.643 & 15 \\
& Total & 6.10 & 5.206 & 16.80 & 3.341 & 16.772 & 30 \\
Interaction & Male & 4.15 & 3.814 & 17.30 & 3.496 & 17.448 & 15 \\
between the & Female & 3.20 & 3.125 & 17.70 & 3.401 & 18.510 & 15 \\
modified and & Total & 3.30 & 3.561 & 17.50 & 3.325 & 17.968 & 30 \\
abstract letters & & & & & & & \\
Traditional & Male & 8.50 & 5.216 & 10.20 & 4.612 & 9.981 & 15 \\
& Female & 14.30 & 5.017 & 14.30 & 2.016 & 13.695 & 15 \\
& Total & 12.25 & 6.028 & 12.25 & 3.921 & 12.015 & 30 \\
Total & Male & 6.00 & 5.211 & 15.37 & 2.976 & 15.482 & 45 \\
& Female & 8.40 & 7012 & 16.85 & 2.578 & 16.921 & 45 \\
& Total & 7.01 & 6.136 & 15.45 & 4.232 & 15.327 & 90 \\
\hline
\end{tabular}

Table (4) shows that there was an apparent contradiction in the arithmetic means and standard deviations in the posttest according to the teaching method and gender. It was noted that the groups of the method of teaching the modified and abstract letters were ranked first with an arithmetic mean of (17.968). It was followed by the groups the method of teaching the modified letter with an arithmetic mean of (16.772) and the traditional method of teaching with an arithmetic mean of (12.015). To show the significance of differences of the arithmetic means, two-way ANCOVA was used, as shown in table (5).

Table 5. Two-Way ANCOVA of the Effect of the Teaching Method and Gender and Their Interaction in the PostTest

\begin{tabular}{ccccccc}
\hline Source of variance & $\begin{array}{c}\text { Total Sum } \\
\text { of Squares }\end{array}$ & $\begin{array}{c}\text { Freedom } \\
\text { Degrees }\end{array}$ & $\begin{array}{c}\text { Means of } \\
\text { Squares }\end{array}$ & $\begin{array}{c}\text { "F" } \\
\text { Value }\end{array}$ & $\begin{array}{c}\text { Statistical } \\
\text { Significance }\end{array}$ & $\begin{array}{c}\text { Impact } \\
\text { Size }\end{array}$ \\
\hline Pre-test & 59.180 & 1 & 59.180 & 5.329 & 0.021 & 0.096 \\
Teaching Method & 462.236 & 2 & 231.18 & 20.613 & 0.000 & 0.189 \\
Gender & 30.518 & 1 & 30.518 & 2.689 & 0.086 & 0.178 \\
Interaction between Gender\& & 46.682 & 2 & 23.341 & 2.217 & 0.135 & 0.269 \\
Teaching Method & & & & & & \\
Error & 568.635 & 83 & 10.653 & & & \\
Total & 1230.658 & 89 & & & & \\
\hline
\end{tabular}

Table (5) shows that there were statistically significant differences of the teaching method, while there were no statistically significant differences due to gender nor interaction between them. To show the significance of differences between the arithmetic means of the performance of the participants according to the teaching method, LSD was used to calculate the modified means to exclude the impact of their performance in the pre-test, as shown in table (6). 
Table 6. Post-Comparisons of the Impact of Teaching Method on the Post-Test

\begin{tabular}{ccccc}
\hline $\begin{array}{c}\text { Teaching } \\
\text { Method }\end{array}$ & $\begin{array}{c}\text { Modified Arithmetic } \\
\text { Mean }\end{array}$ & Modified Letter & Modified+ Abstract & Traditional \\
\hline Modified Letter & 16.772 & & \\
Modified + & 17.968 & 1.296 & \\
Abstract & & & $* 6.392$ & \\
Traditional & 12.015 & $* 6.358$ & $*$ & \\
\hline
\end{tabular}

* Significant at $(\alpha=0.05)$

Table (6) shows that there were statistically significant differences between the students who were taught in the traditional way and those of the group that was taught using the teaching method of the modified letter and those taught using the teaching method of both modified and abstract letters, favoring the students who were taught using the teaching method of both modified and abstract letters with an arithmetic mean of (17.968).

To answer the second question "i.e. does the performance of students with learning disabilities differ in learning the similar English language letters in the follow-up test with the difference of the teaching method, gender, and interaction?", the arithmetic means, standard deviations, and modified means were calculated, as shown in table (7).

Table 7. Arithmetic Means, Standard Deviations, and Modified Means of the Performance of the Participants in the Follow-Up Test According to the Teaching Method and Gender

\begin{tabular}{cccccccc}
\hline & \multicolumn{2}{c}{ Pre-test } & \multicolumn{5}{c}{ Follow-up test } \\
\hline $\begin{array}{c}\text { Teaching } \\
\text { Method }\end{array}$ & Gender & $\begin{array}{c}\text { Arithmeti } \\
\text { c Mean }\end{array}$ & $\begin{array}{c}\text { Standard } \\
\text { Deviation }\end{array}$ & $\begin{array}{c}\text { Arithmetic } \\
\text { Mean }\end{array}$ & $\begin{array}{c}\text { Standard } \\
\text { Deviation }\end{array}$ & $\begin{array}{c}\text { Modified } \\
\text { Means }\end{array}$ & Number \\
\hline Modified & Male & 5.65 & 5.239 & 17.98 & 2.219 & 18.018 & 15 \\
Letter & Female & 6.43 & 5.150 & 18.86 & 2.043 & 18.723 & 15 \\
& Total & 6.10 & 5.206 & 18.45 & 2.015 & 18.431 & 30 \\
Interaction & Male & 4.15 & 3.814 & 17.85 & 2.971 & 18.132 & 15 \\
between the & Female & 3.20 & 3.125 & 18.80 & 2.240 & 19.425 & 15 \\
abstract and & Total & 3.30 & 3.561 & 18.30 & 2.664 & 18.829 & 30 \\
modified & & & & & & & \\
Traditional & Male & 8.50 & 5.216 & 10.15 & 4.314 & 9.980 & 15 \\
& Female & 14.30 & 5.017 & 11.30 & 3.126 & 10.645 & 15 \\
& Total & 12.25 & 6.028 & 10.85 & 3.486 & 10.286 & 30 \\
Total & Male & 6.00 & 5.211 & 15.30 & 4.945 & 15.352 & 45 \\
& Female & 8.40 & 7012 & 17.10 & 3.978 & 16.913 & 45 \\
& Total & 7.01 & 6.136 & 16.882 & 3.738 & 16.761 & 90 \\
\hline
\end{tabular}

Table (7) shows that there was an apparent contradiction in the arithmetic means and standard deviations in the follow-up test according to the teaching method and gender. It was noted that the groups of the method of teaching the modified and abstract letters were ranked first with a modified mean of (18.829). It was followed by the groups the method of teaching the modified letter and the traditional method of teaching with arithmetic means of (18.431) and (10.286), respectively. To show the significance of differences of the arithmetic means, two-way ANCOVA was used, as shown in table (8). 
Table 8. Two-Way ANCOVA of the Impact of the Teaching Method and Gender and Their Interaction in the Follow-Up Test

\begin{tabular}{ccccccc}
\hline Source of variance & $\begin{array}{c}\text { Total Sum } \\
\text { of Squares }\end{array}$ & $\begin{array}{c}\text { Freedom } \\
\text { Degrees }\end{array}$ & $\begin{array}{c}\text { Means of } \\
\text { Squares }\end{array}$ & $\begin{array}{c}\text { "F" } \\
\text { Value }\end{array}$ & $\begin{array}{c}\text { Statistical } \\
\text { Significance }\end{array}$ & $\begin{array}{c}\text { Impact } \\
\text { Size }\end{array}$ \\
\hline Pre-test & 67.210 & 1 & 67.210 & 9.643 & 0.004 & 0.168 \\
Teaching Method & 992.256 & 2 & 496.13 & 73.215 & 0.000 & 0.512 \\
Gender & 17.023 & 1 & 17.023 & 2.453 & 0.138 & 0.243 \\
Interaction between Gender\& & 3.146 & 2 & 1.573 & 0.143 & 0.860 & 0.176 \\
Teaching Method & & & & & & \\
Error & 385.379 & 83 & 7.886 & & & \\
Total & 1538.628 & 89 & & & & \\
\hline
\end{tabular}

Table (8) shows that there were statistically significant differences of the teaching method, while there were no statistically significant differences due to gender nor interaction between them. To show the significance of differences between the arithmetic means of the performance of the participants according to the teaching method, LSD was used to calculate the modified means to exclude the impact of their performance in the pre-test, as shown in table (9).

Table 9. Post-comparisons of the Impact of Teaching Method on the Follow-Up Test

\begin{tabular}{ccccc}
\hline Teaching Method & $\begin{array}{c}\text { Modified Arithmetic } \\
\text { Mean }\end{array}$ & Modified Letter & Modified+ Abstract & Traditional \\
\hline Modified Letter & 18.431 & & & \\
Modified + & 18.829 & -0.614 & & \\
Abstract & & & $* 10.706$ & \\
Traditional & 10.286 & $* 10.352$ & & \\
\hline
\end{tabular}

* Significant at $(\alpha=0.05)$

Table (9) shows that there were statistically significant differences between the performance of the students who were taught in the traditional way and those of the group that was taught using the teaching method of the modified letter and those taught using the teaching method of both modified and abstract letters, favoring the students who were taught using the teaching method of both modified and abstract letters with an arithmetic mean of (18.829).

\section{Discussion of Results}

Results showed that there were statistically significant differences that could be attributed to the teaching method in favor of the group that used the teaching method of both modified and abstract letters. Additionally, there were no statistically significant differences in gender and interaction between the teaching method and gender. The statistically significant differences due to the teaching method could be interpreted because of the effectiveness of the strategy that used the modified and abstract letters and the ability to raise students' attention and interest in the educational material as it helped them remember the letters by creating a visual link between the modified letter and the abstract one it indicated leading to the matching between them. In other words, the student attempted to draw a mental image of the abstract letter and to match its shape with that of the image, helping learn the letter and differentiate it from a similar one. Learning and recall of the letter are the totals of recalling with a mental image of the modified letter to a familiar image. It was characterized by including the elements of excitement, e.g. colors and drawings. Furthermore, the novelty of the teaching method motivated the participants to interact with, indicating the availability of motivation in pictured letters strategy.

This matched the results of many studies that tackled the effectiveness of pictured letters mnemonics strategy in developing the students with learning disabilities. For example, Agramonte and Belfiore (2002) concluded that this strategy caused the increase of the ratio of learning consonant letters and sounds among students with learning disabilities. Raschke, Alpper and Eggers (1999) and Sehlberg, Barendregt, and Rubens (2011) illustrated that using pictured letters Mnemonics strategy made learning letters more fun. The results of the study also matched those of 
other studies that tackled the effectiveness of this strategy (e.g. Shmedman and Ehri, 2010; Manalo, Mizutani, and Trafford, 2004).

The lack of impact due to gender could be interpreted to be the result of the effectiveness of pictured letters mnemonics strategy in developing memory skills and improving learning similar English language letters among students with learning disabilities, regardless of gender, supporting the adoption of this strategy. This matched the results of Elayed (2007).

The present study concluded that there was no interaction between the teaching method and gender in the post-test because gender is a variable independent from learning disabilities. Thus, a student may experience learning disabilities, regardless gender. This matches the interpretation of Elzofaery and Aboelfakhr (2005).

\section{Conclusion}

Training on the use of pictured letters mnemonics strategy in learning similar English language letters is a significant issue in developing the memory and learning skills of students with learning disabilities. It positively impacts their performance. Therefore, the results of the present study agree with the literature reporting that training on using pictured letters mnemonics strategy is a key factor in developing the memory and learning skills of students. Hence, if it is adopted by the teachers and those in charge of this type of students, it obviously affects the retention of information for a longer time, utilizing and distinguishing English language letters which enable the student to benefit from this language, raising the potential to generalization, and motivating the student to learning, in general, and to learning English language, in particular.

\section{Recommendations}

- Using pictured letters mnemonics strategy in teaching the modified and abstract letters for the students with learning disabilities in the similar English language letters who have similar features to those of the current study's participants.

- Investigating the effectiveness of pictured letters mnemonics strategy in teaching the modified and abstract letters for the students with other cognitive handicaps.

\section{References}

Agramonte, V., \& Belfiore, J. (2002). Using mnemonics to increase early literacy skills in urban kindergarten students. Journal of Behavioral Education, 11(3), 181-190. https://doi.org/10.1023/A:1020178020059

DiLorenzo, E., Rody, A., Bucholz, L., \& Brady, P. (2010). Teaching letter sound connections with picture mnemonics: Itchy's alphabet and early decoding. Preventing School Failure, 55(1), 28- 34. https://doi.org/10.1080/10459880903286763

Elayed, W. (2007). The impact of a training program on developing the memory and achievement of students with learning disabilities (Unpublished Ph.D. dissertation). The University of Jordan, Jordan.

Elzofaery, N., \& Aboelfakhr, G. (2005). Differences between the $5^{\text {th }}$ grade students with learning disabilities and the normal in the performance of the short-term memory. Damascus University Journal, 21(2), 303-331.

Hallahan, D., Lloyd, J. Kauffman, J. Wiess, M., \& Martinez, E. (2007). Learning disabilities: Foundations, characteristics, and effective teaching (Trans: Adel Abdullah). Amman: Dar Elfekr Publishers \& Distributors.

Manalo, E., Mizutani, S., \& Trafford, J. (2004). Using mnemonics to facilitate learning of Japanese script characters. JALT Journal, 26(1), 55-78.

Mastropieri, A., Sweda, J., \& Scruggs, E, (2000). Putting Mnemonics strategies to work in an inclusive classroom. Learning Disabilities Research \& Practice, 15(2), 69-74. https://doi.org/10.1207/SLDRP1502_2

Mather, N., \& Healey, C. (1984). The efficacy a memory strategy for eliminated reversal behavior. Journal of Learning Disabilities, 17(2), 84-88. https://doi.org/10.1177/002221948401700206

Miqdad, Q., \& Kanana, M. (2014). The effectiveness of pictured letters as an aid in learning the similar Arabic letters among students with learning disabilities. The Jordanian Journal of Educational Sciences, 10(2).

Rack, M. (2005). Learning Disabilities: A handbook for Instructors and tutors. Overland. Kansas: Johnson County Community College. 
Raschke, D., Alper, S., \& Eggers, E. (1999). Recalling alphabet letter names: A mnemonic system to facilitate learning. Preventing School Failure, 43(2), 80-83. https://doi.org/10.1080/10459889909603306

Sehlberg, T., Barendregt, W., \& Rubens, N. (2011). Kanji Learning Lab: Memorizing Kanji in a playful way. Proceedings of the European Conference on Games Based Learning, pp543-552. https://doi.org/10.1007/s10864-005-2705-x

Sener, U., \& Belfiore, P. (2005). Mnemonics strategy development: Improving alphabetic understanding in Turkish students, at risk for failure in EFL settings. Journal of Behavioral Education, 14(2), 105-115. https://doi.org/10.1080/10888430903117492

Shmedman, A., \& Ehri, L. (2010). Embedded picture mnemonics to learn letters. Scientific Studies of Reading, 14(2), 159-182.

Steele, M. (2007). Teaching science to students with learning differences. Science Teacher, 74(2), 24-27.

White, T. (2006). The effects of mnemonics on letter recognition and letter sound acquisition of at-risk kindergarten students (Unpublished Ph.D. dissertation). Texas A\&M University, USA.

Yahya, K. (2007). Teaching reading, writing and pronunciation to those with special needs. Amman: Dar Al Massira For Publishing, Printing \& Distribution. 